\title{
Surface Roughness Based Characterization of Slip Band for Damage Initiation in a Nickel Base Superalloy
}

\author{
Hsin shen HO $^{1 *}$, Marion RISBET ${ }^{2}$, Xavier FEAUGAS ${ }^{3}$, Maxence BIGERELLE ${ }^{4}$, \\ Erliang ZHANG ${ }^{1}$
}

${ }^{1}$ School of Mechanical Engineering and Henan Key Engineering Laboratory for Anti-Fatigue Manufacturing Technology, Zhengzhou University, Science Road 100, 450001 Zhengzhou, China

${ }^{2}$ Laboratoire Roberval UMR CNRS 7337, Université de Technologie de Compiègne, Centre de Recherches de Royallieu, BP 20529 - 60205 Compiègne cedex, France

${ }^{3}$ Laboratoire des Sciences de l'Ingénieur pour l'Environnement, UMR CNRS 7356, Université de La Rochelle, Avenue Michel Crépeau, 17000 La Rochelle cedex, France

${ }^{4}$ Equipe Matériaux, Surfaces et Mise en forme, TEMPO, LAMIH, Université de Valenciennes, Campus Mont Houy, 59313

Valenciennes Cedex 9, France

crossref http://dx.doi.org/10.5755/j01.ms.24.1.17684

Received 04 March 2017; accepted 01 May 2017

\begin{abstract}
This work presents a computational protocol, based on a variance analysis integrated with the bootstrap method, to investigate surface damage resulting from localization of plastic deformation in slip bands of a Ni-base superalloy. For assessment of fatigue crack initiation, surface roughness is introduced to quantify the degree of slip irreversibility. The contribution of this study is to provide a most relevant roughness parameter that can extract the salient features of slip bands within damaged grains, and thus enabling the discrimination of damaged and undamaged grains for description of fatigue-induced surface damage. Results suggest that the maximum peak height $\left(S_{p}\right)$ is the most relevant parameter. And a very pronounced variability of $S_{p}$ values is observed for damaged grains.

Keywords: surface roughness, surface damage, plastic strain localization, atomic force microscopy, Ni-base superalloy.
\end{abstract}

\section{INTRODUCTION}

Fatigue damage of materials that exhibit flow localization is often related to a surface phenomenon [1]. Under fatigue loading, slip bands emerge in the form of extrusions and/or intrusions on the material surface as a consequence of the localization of plastic deformation induced by irreversible motion of dislocations [1-6]. For face-centered cubic alloys, intragranular crack initiation is favored at the site of surface roughness developing a critical notch-peak geometry, i.e. the interface between slip band and matrix $[7,8]$. The latter, serving as the preferential site for fatigue crack initiation, is a plane of discontinuity across which there are abrupt gradients in the density and distribution of dislocations [2].

As crack initiation mechanism is dominated by the localization of plastic strain in slip bands, many studies have focused on the examination of the topographical features of fatigue-induced slip bands. According to a review [9], two types of cyclic strain localizations, namely persistent slip bands (PSBs) and shear bands (SBs), can be distinguished at a lower plastic value of maximum strain $\left(\varepsilon_{\max }\right)$. Though they are different in structure and crystal orientation [10], they are very often incorrectly used interchangeably. Recently, the precise nature of these bands has carefully been elucidated to clear up the confusion [4]. Unlike PSBs, SBs are generally formed by ribbon-like structure extrusions with a wavy character $[4,11]$. SBs are found to have higher values of the variance associated with the mean height emergence of deformation bands, corresponding to a larger fluctuation of the extrusion height along each band [2, 4-6]. The reversibility of strain is also naturally higher in SBs than PSBs as a result of the formation of lower mean extrusion height [4].

Surface roughness, representing the arisen surface marking from material surface, has been studied as an indirect measure of the local irreversibility [4-6, 13]. And the parameter called arithmetical mean deviation of the roughness profile $\left(R_{a}\right)$, which is defined as the averaged absolute deviation of the roughness irregularities from the mean line over one sampling length, is commonly used for characterization of the height emergence of slip bands. In these works, the growth of slip bands is found to be saturated at a specific height up to the end of the fatigue life. As $R_{a}$ contains only filtered information on potentially critical surface grooves and/or asperities [14], it may perhaps be inappropriate to assess the complexity of the slip band structure with respect to surface damage initiation. Therefore, effort is made in the present work to address the issue questioning the pertinence of an appropriate roughness parameter that should be used for description of surface crack initiation morphology.

Thus, identification of a most relevant roughness parameter that can extract the salient features of slip bands associated with crack initiation is the main concern of the present work, with the ultimate aim to understand from a

\footnotetext{
*Corresponding author. Tel.: +86-371 67781235.
}

E-mail address: hsinshen.ho@zzu.edu.cn (H.S. Ho) 
topographical point of view, why certain grains are damaged while others are not. To tackle this issue, a computational protocol is established considering the amplitude surface roughness parameters of ISO 25178-2012 [15]. The proposed methodology is applied to the surfaces of a Nibase superalloy (Waspaloy) treated with chemical-etching and electro-polishing.

\section{MATERIAL AND METHODS}

\subsection{Material}

The target material is a Ni-base superalloy (Waspaloy) strengthened by spherical precipitates $\left(\gamma^{\prime}, \mathrm{Ni}_{3} \mathrm{Al}\right)$ with the following chemical compositions (in wt.\%): $1.80 \mathrm{Al}$; 3.33 Ti; $12.64 \mathrm{Co} ; 19.45 \mathrm{Cr} ; 7.31 \mathrm{Mo}$; balance Ni. The average grain size is $100 \mu \mathrm{m}$ and the average precipitate size is $17 \mathrm{~nm}$. In the present study, precipitate sizes less than $50 \mathrm{~nm}$ are assessed in order to remain in the dislocationparticle shearing deformation mode (under-aged state).

\subsection{Experimental procedure}

The specimens are mechanically polished up to 4000 grit $\mathrm{SiC}$ paper $(\sim 5 \mu \mathrm{m})$, then chemically treated; one is etched in a mixture composed of $2 / 3$ hydrochloric acid and $1 / 3$ nitric acid for a duration of $1.30 \mathrm{~min}$, denoted as WC, while the other one is electro-polished in a mixture constituted of $80 \mathrm{ml}$ perchloric acid, $700 \mathrm{ml}$ ethanol, $100 \mathrm{ml}$ 2-butoxy ethanol, $120 \mathrm{ml}$ distilled water under the following condition: $\sim 1.30 \mathrm{~min},-10^{\circ} \mathrm{C}$ and 35 volts direct current, designated as WE.

Interrupted low-cycle fatigue tests are conducted on hourglass cylindrical specimens with a gauge length of $15 \mathrm{~mm}$ and a gauge diameter of $6 \mathrm{~mm}$ under a controlled plastic strain amplitude $\left(\Delta \varepsilon_{p} / 2\right)$ of $0.3 \%$ with a fully reversed triangular wave form at a frequency of $0.05 \mathrm{~Hz}$ until the nucleation of first cracks. The surface states are characterized by scanning electron microscope (SEM) and atomic force microscope (AFM), using respectively a (FEG) Zeiss Sigma SEM and a Veeco Dimension 3100 AFM (see Ref. [4] for details). For the detection of extrusion and quantitative analysis of extrusion growth, the region free of initial flaws of $10 \mu \mathrm{m} \times 10 \mu \mathrm{m}$ is measured per grain. For each specimen, 16 regions of different grains, including 8 damaged grains and 8 undamaged grains, are investigated, and for each grain, more than 20 slip bands are assessed. In addition to the surface analysis, the bulk of the material is examined using JEOL JEM2011 transmission electron microscope (TEM) operating at $200 \mathrm{kV}$. Thin foils of $3 \mathrm{~mm}$ in diameter and $100 \mu \mathrm{m}$ in thickness are prepared for TEM investigations.

The measured surface topographies are characterized only by seven amplitude surface roughness parameters which are frequently used to measure the vertical characteristics of the surface deviations [14]. As the morphology of the extrusion formation are favorably attributed to the glide of mobile dislocations throughout the band, i.e. the well-defined and narrow slip bands emerge in the form of only extrusions in the $z$-direction on the material surface under low-cycle fatigue loading, these seven amplitude surface roughness parameters are thus considered as the most important and appropriate parameters to characterize the surface topographies investigated in the present study. These surface roughness parameters listed in Table 1 are computed in agreement to ISO 25178-2012 [15]. The assessment of a most relevant parameter for characterizing the salient features of slip bands within damaged grains is based on the coupling of an analysis of variance (ANOVA) [16] with bootstrap method [17].

Bootstrapping is implemented, due to a limited amount of available experimental data set assumed to be from an independent and identically distributed population, to affirm the relevance of obtained results by providing a confidence interval that allows integrating the variability of roughness data into ANOVA. This method, relying on the resampling with replacement technique, consists in generating a high number $M(=1000)$ of simulated bootstrap sets of samples of size $K(=16$ per specimen) from the experimental data set of the same size $K$. For each roughness parameter, the bootstrap set of $M$ values is used to construct an empirical probability density function (PDF), which is then used in ANOVA. In ANOVA, the $F$-statistic is calculated for each roughness parameter considering damaged and undamaged grains. This statistical index is computed as the ratio of the between-groups variance in the data over the pooled (average) within-group variance. The $F$-statistic average is then used to rank the roughness parameters with regard to their ability to discriminate between damaged and undamaged grains, and thus the first-ranked parameter is the most relevant parameter for description of topographical features associated with crack initiation.

Table 1. Surface roughness parameters used in the present study

\begin{tabular}{|l|l|l|}
\hline \multicolumn{3}{|l|}{$\begin{array}{l}\text { ISO 25178 (2012) [15] } \\
\text { Amplitude parameters }\end{array}$} \\
\hline$S_{a}$ & $\begin{array}{l}\text { Arithmetic } \\
\text { mean height }\end{array}$ & $S_{a}=\frac{1}{L_{1} L_{2}} \int_{0}^{L_{1}} \int_{0}^{L_{2}}|f(x, y)-\bar{f}| \mathrm{d} x \mathrm{~d} y$ \\
\hline$S_{q}$ & $\begin{array}{l}\text { Root mean } \\
\text { square } \\
\text { height }\end{array}$ & $S_{q}=\sqrt{\frac{1}{L_{1} L_{2}} \int_{0}^{L_{1}} \int_{0}^{L_{2}}(f(x, y)-\bar{f})^{2} \mathrm{~d} x \mathrm{~d} y}$ \\
\hline$S_{k u}$ & $\begin{array}{l}\text { Kurtosis } \\
L_{1}\end{array}$ & $S_{k u}=\frac{1}{L_{1} L_{2} S_{q}^{4}} \int_{0}^{L_{2}} \int_{0}^{L_{1}}(f(x, y)$ \\
\hline$S_{s k}$ & $\begin{array}{l}\text { Skewness } \\
L_{1}\end{array}$ & $S_{s k}=\frac{1}{L_{1} L_{2} S_{q}^{3}} \int_{0}^{L_{2}} \int_{0}^{4}(f(x, y)$ \\
\hline$S_{z}$ & $\begin{array}{l}\text { Maximum } \\
\text { height }\end{array}$ & $S_{z}=S_{p}+S_{v}$ \\
\hline$S_{p}$ & $\begin{array}{l}\text { Maximum } \\
\text { peak height }\end{array}$ & $S_{p}=\max (f(x, y)-\bar{f})$ \\
\hline$S_{v}$ & $\begin{array}{l}\text { Maximum } \\
\text { pit height }\end{array}$ & $S_{v}=\min (f(x, y)-\bar{f})$ \\
\hline $\begin{array}{l}\text { where } \bar{f} \text { is the height of the mean plane, } L_{1} \text { and } L_{2} \text { are the } \\
\text { extent of the sample and } f(x, y) \text { is the surface height at the } \\
\text { location }(x, y) .\end{array}$ \\
\hline
\end{tabular}




\section{RESULTS AND DISCUSSION}

\subsection{Surface state $v s$. crack initiation life}

Table 2. Metallurgical states of the specimens investigated in the present study

\begin{tabular}{|l|c|c|c|l|c|c|c|}
\hline Specimen & $D, \mu \mathrm{m}$ & $d, \mathrm{~nm}$ & $I_{d}, \mathrm{~nm}$ & Surface treatment method & $S_{a}, \mathrm{~nm}$ & $\Delta \varepsilon_{p} / 2, \%$ & $N_{i}$, cycle \\
\hline WC & \multirow{2}{*}{100} & \multirow{2}{*}{30} & Chemical etching & 13.3 & 0.3 & 700 \\
\cline { 1 - 1 } & & & & Electro-polishing & 0.72 & 0.3 & 800 \\
\hline
\end{tabular}

The metallurgical states of WC and WE, which are the specimens investigated in this study, are presented in Table 2. The surface states of both preparations are discussed using arithmetic mean deviation $\left(S_{a}\right)$ computed prior to fatigue tests with respect to the number of cycles required for crack initiation $\left(N_{i}\right)$. It is worth noting that $S_{a}$, the three-dimensional counterpart of the two-dimensional descriptor $R_{a}$, is commonly used to describe an overall measure of the texture comprising the surfaces $[4-6,13]$. The electro-polished surface (with $S_{a} \approx 0.72 \mathrm{~nm}$ ) is found to be smoother compared to the chemically-etched one (with $S_{a} \approx 13.3 \mathrm{~nm}$ ), which offers a slightly greater fatigue crack initiation life of $\sim 100$ cycles (Fig. 1). This finding shows that surface preparation method affects surface state, which in turn can influence fatigue crack initiation life $\left(N_{i}\right)$. Indeed, cracks nucleate preferably at the sites of initial surface roughness which have developed a critical notch-peak geometry acting as potential stress raiser that can accelerate crack initiation process [18].

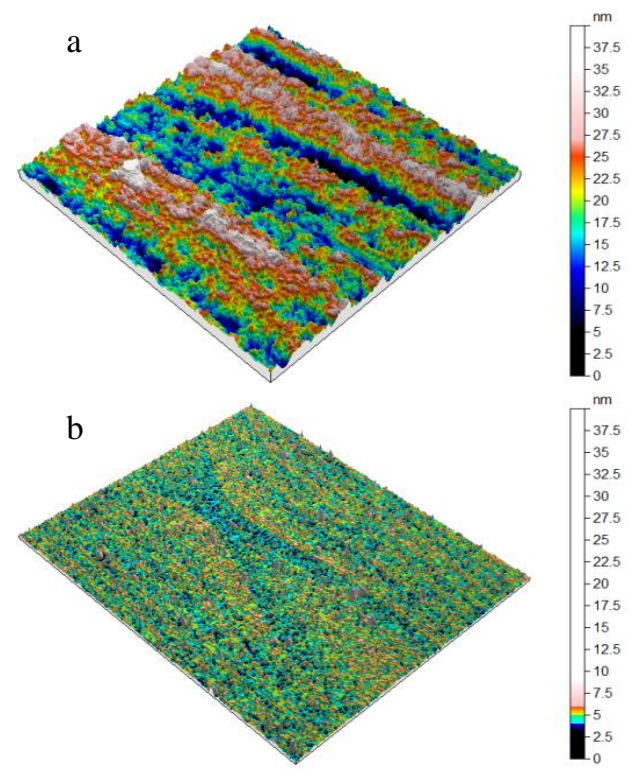

Fig. 1. 3D surface representation: a - chemically-etched specimen (WC) and b - electro-polished specimen (WE)

Fig. 2 illustrates surfaces of WC (Fig. 2 a) and WE (Fig. 2 b) at the crack initiation phase (when $N=N_{i}$ ). In these SEM micrographs, slip bands, grain boundaries and intragranular cracks are observed. Regardless of surface states, cracks are nucleated principally along slip bands as a result of the localization of plastic deformation induced by irreversible motion of dislocations [5-7]. Besides, these cracks are prone to initiate along the bands with slips that are particularly intense $[7,18]$. Indeed, bands that are narrow and well-defined have a very large stress concentrator effect, giving rise to both internal and external crack initiation [7].

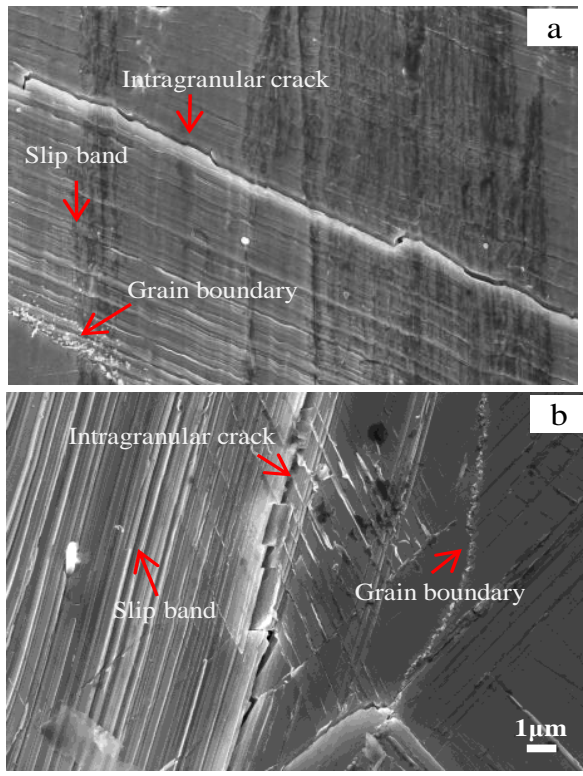

Fig. 2. Microstructures in the crack initiation phase: $\mathrm{a}$-chemically-etched specimen (WC); b-electro-polished specimen (WE)

The secondary slip systems, which are present in limited quantities, are also activated especially near grain boundaries and triple junctions. As the investigated region of $10 \mu \mathrm{m} \times 10 \mu \mathrm{m}$ is situated within the grain of only one slip system being activated [19], the effect of matrix-grain and matrix-precipitate with grain boundary can thus be assumed to be insignificant. Though the role of grain boundary in crack initiation has long been known $[1,20]$, it is worth noting that they do not participate in the mechanism of fatigue crack initiation in the present work. Moreover, the deformation structures observed in the bulk by TEM is found to be well correlated with the ones observed on the specimen surface by AFM, suggesting that there is not any significant depth-dependent self-affine behavior due to surface proximity.

To assess the complexity of slip band structures in order to reveal the characteristic features of slip bands, two roughness parameters are investigated $-S_{s k}$ and $S_{k u}$. The former qualifies the symmetry of the height distribution while the latter characterizes the flatness of the height distribution. For all investigated specimens, $S_{s k}$ and $S_{k u}$ are found to be larger than 0 and 3 , respectively. Positive 
skewness describes surfaces with lots of high peaks while $S_{k u}$ larger than 3 implies a high degree of peakedness of the surface height distribution. By combining both parameters, spiky surfaces with high peaks are obtained (Fig. 3). This finding is found to be well correlated with the morphology of the extrusion associated with the shear band structure, indicating the presence of ribbon-like structure extrusions with a wavy character and with their height variation that can go up to $250 \%[5,6,11,12]$. Besides, the extrusions on chemically etched (Fig. 3 a) are found to be wavier than that on electro-polished (Fig. 3 b), i.e. their height fluctuate slightly more along the intersections slip bands with the grain polishing lines at the specimen surface, and thus reflecting the original roughness of chemically-etched surface that is created prior to fatiguing.
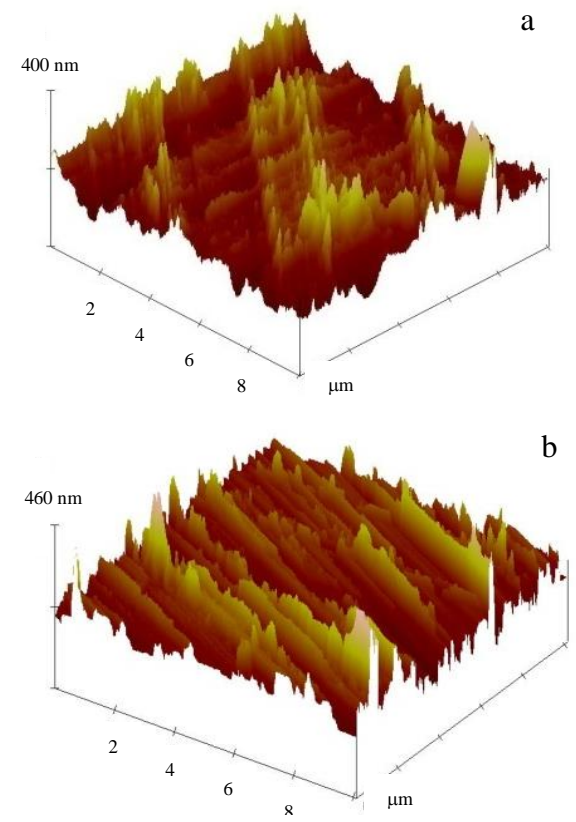

Fig. 3. Surface topographies in the crack initiation phase obtained by AFM: $a-W C ; b-W E$

\subsection{Cyclic deformation behavior}

The cyclic hardening/softening curves of the investigated specimens are shown in Fig. 4, illustrating the evolution of alternating stress $\left(\sigma_{a}\right)$ as a function of number of cycle $(N)$. Three principal cyclic evolution stages are identified: cyclic hardening, peak and cyclic softening. The increase in flow stress is called cyclic hardening, corresponding to the accumulation of dislocations within intense deformation bands throughout the grains [21]. With continued cyclic straining, the cyclic flow stress attains the maximal value at the peak of the curve and decreases thereafter, implying a reduced resistance to deformation. The reduction in cyclic stress amplitude is denoted as cyclic softening and its occurrence is principally resulted from the shearing process of precipitates by dislocations and the partial relaxation of long-range internal stresses [7].

In Fig. 4, it is observed that cyclic softening begins as early as $\sim 30$ cycles for both WC and WE. This finding implies that the presence of easily shearable precipitates, referring to precipitates that are especially fine $(d=17 \mathrm{~nm})$, closely spaced $\left(I_{d} \approx 30 \mathrm{~nm}\right)$ and coherent with the matrix, favors the softening phenomenon as a result of the plastic deformation mechanism that causes fatigue crack initiation. Besides, the flow stress amplitude of WC is exhibited to be slightly higher than that of WE. The difference of systematic $30 \mathrm{MPa}$ shift of maximum stress level of WC is noted to be associated to the metallurgical states such as precipitate size and grain size but certainly not on the surface treatment method [1,22]. Indeed, the grain size of $\mathrm{WC}$ is approximated to be $\sim 130 \mu \mathrm{m}$ and the one of WE is estimated to be $\sim 140 \mu \mathrm{m}$. Though, these grain sizes can be considered to be the same. This is because the difference in strength $(\Delta \sigma)$ between the largest and the smallest mean grain sizes calculated using the Hall-Petch law is equal to 3.9 $\mathrm{MPa}$, which can be considered as negligible from the metallurgical point of view; for the sake of simplicity, the mean grain size of $100 \mu \mathrm{m}$ is considered for the two specimens investigated in the present study. Consequently, the state of the surface has only negligible effect on the fatigue strength in the present study.

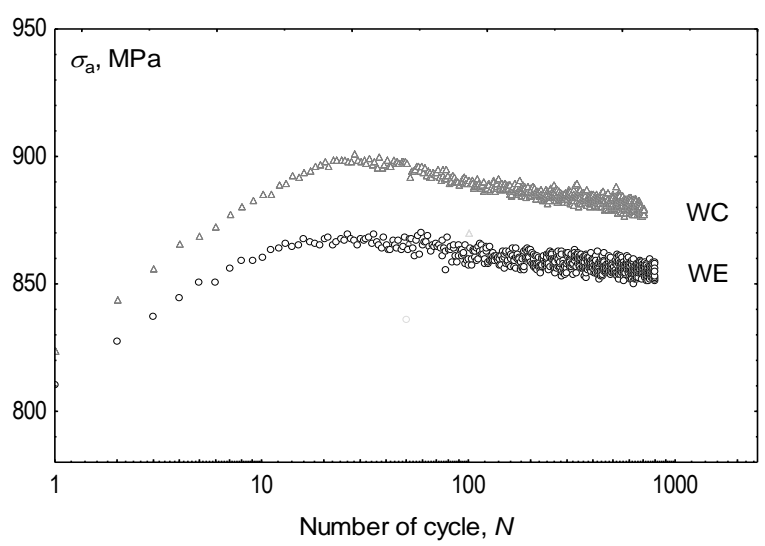

Fig. 4. Cyclic hardening/softening curves of electro-polished (WE) and chemically-etched (WC) specimens.

\subsection{Kinetics of slip band formation}

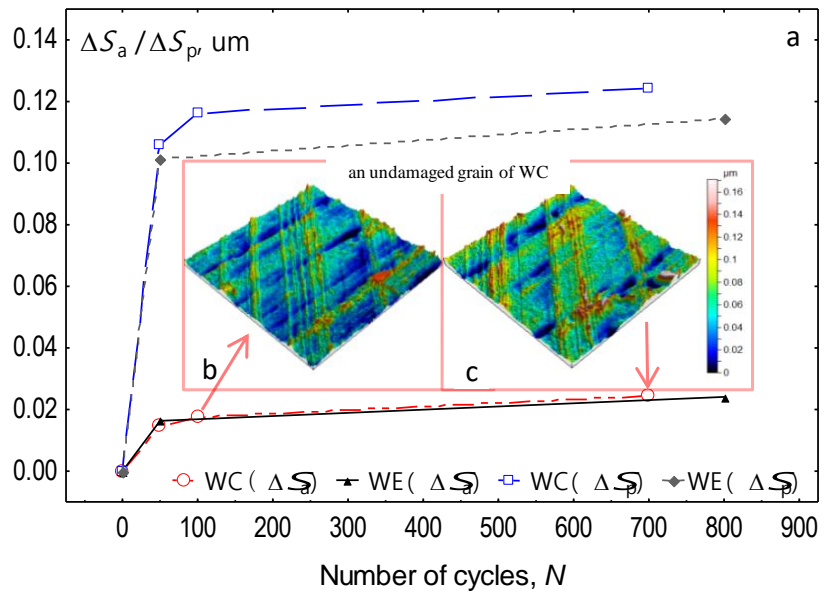

Fig. 5. a-evolution of $\Delta S_{\mathrm{a}}$ and $\Delta S_{\mathrm{p}}$ versus $N$, and the 3D representation of surfaces of a chemically-etched grain obtained at $b-100$ cycles and $c-700$ cycles.

In Fig. 5, the increment of the arithmetic mean height $\left(\Delta S_{a}=S_{a}(N)-S_{a}\left(N_{0}\right)\right)$ is computed as a function of the number of cycles $(N), N_{0}=0 . \Delta S_{a}$ (or $\Delta S_{p}$ ) is exhibited to be monotonically increasing with $N$ until $N_{i}$, i.e. surfaces become progressively rougher before the nucleation of the first intragranular cracks (see Fig. 5 b, c), in agreement with 
the results obtained for ferritic $\mathrm{X} 10 \mathrm{CrAl} 24$ stainless steel [6]. Besides, the small difference in $\Delta S_{a}$ (or $\Delta S_{p}$ ) found for both surface states WC and WE shows that $\Delta S_{a}$ (or $\Delta S_{p}$ ) does not depend on the surface preparation method, and thus more supporting hypothesis that surface state hase only insignificant effect.

Though the roughness height increases continually with $N$, the rate at which the surface is roughened is found to decrease gradually especially when $N>100$. This is because under continued cycling, the production of a low vacancy concentration and of a large variety of defect types (e.g. cluster of point defects, prismatic loops, dipoles, multipoles and especially paired dislocations presented in Fig. 6) in slip bands becomes pronounced, making the movement of mobile dislocations that transport the plastic deformation more difficult and as a consequence, reduces the slip reversibility, and thus the process that produces the extrusions is self-limiting in terms of the rate [4]. It is worth noting that the degree of the plastic strain reversibility depends on a large variety of microscopic features such as the density of mobile dislocations, the level of defects density and the condensation of the vacancies that are produced in the bands.

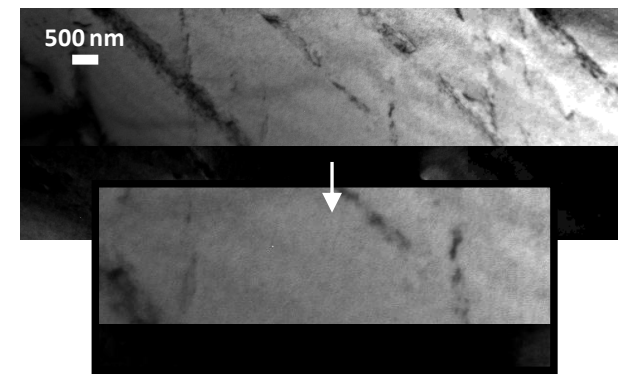

Fig. 6. Bright-field TEM micrographs illustrating deformation bands with paired dislocations in fatigued specimens

\subsection{Relevant roughness parameter}

The most relevant roughness parameter for description of fatigue-induced surface damage is searched using the ANOVA method. The roughness parameters that are classified according to their $F$-statistic average value are illustrated in Fig. 7 a; the term classification order refers to the ranking of the parameter in terms of the $F$-statistic average value, demonstrating the pertinence of the parameter for description of surface fatigue damage and for discrimination of damaged and undamaged grains for both surface states (WC and WE). The first-ranked parameter is the maximum peak height $\left(S_{p}\right)$, accordingly it is identified as a most relevant roughness parameter that can extract the salient features of slip bands associated with crack initiation.

Fig. $7 \mathrm{~b}$ shows the distributions of $S_{p}$ for both damaged and undamaged grains. It is worth noting that the distributions are quite distinct from each other, confirming the ability of $S_{p}$ to extract the inherent features of slip bands within damaged grains, and thus enabling the discrimination of damaged and undamaged grains. Besides, it is observed that $0.11 \mu \mathrm{m}$ is a threshold limit value, beyond which all the grains are damaged. This finding implies that cracks are initiated when $S_{p}$ attains an extreme limit value, i.e. when a critical value of the local irreversible plastic strain accumulated in the slip bands is reached, the dislocation structures in the bands are unable to accommodate any further plastic deformation, and thus promoting the initiation of cracks along slip bands that are particularly intense [1, 4]. When $S_{p}>0.11 \mu \mathrm{m}$, it is shown that there is a sufficient mutual overlapping between adjacent distributions of damaged grains for both surface states WC and WE, indicating that the height between the highest peak and the mean plane of damaged grains is rather similar regardless of surface state. In addition, the distributions of damaged grains are exhibited to be quite broad, suggesting that the estimated PDFs of $S_{p}$ possess a significant variability. And this variability is dependent on the local microstructure (e.g. precipitate size and grain orientation) of examined grain and the environment (e.g. oxygen interstitials) [1,21-23]. It is worth noting that the local microstructure and the environment, known to influence fatigue crack initiation, play a non-negligible role on the irreversible motion and the free glide of mobile dislocations during cyclic loading.

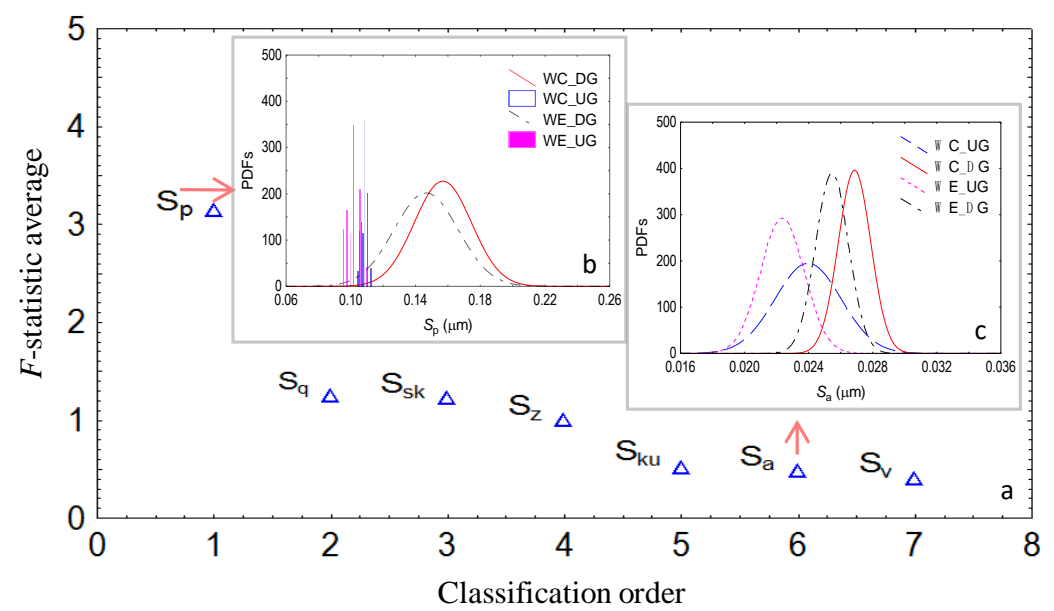

Fig. 7. a-classification order of the relevance of a roughness parameter to describe the salient feature of slip band associated with crack initiation. PDFs of $\mathrm{b}-S_{\mathrm{p}}$ and of $\mathrm{c}-S_{\mathrm{a}}$ for the examined damaged grains (DG) and undamaged grains (UG) of chemically etched and electro-polished specimens 
With regards to the relevance of roughness parameters used for describing investigated surface topographies, the sixth position of the ranking is held by the parameter $S_{a}$. Fig. $7 \mathrm{c}$ shows that all the distributions overlap each other severely, suggesting the inability of this parameter to differentiate damaged and undamaged grains, and thus more supporting hypothesis that the widely-used parameter $S_{a}$ is inappropriate to assess the complexity of slip band structure with respect to surface damage initiation.

\section{CONCLUSIONS}

The topographical features of slip bands in polycrystals Waspaloy has been conscientiously analyzed using seven amplitude surface roughness parameters, the pertinent with respect to fatigue crack initiation has been identified using a method of statistical analysis established in the present work. The proposed roughness parameter called the maximum peak height $\left(S_{p}\right)$ can serve as a good indicator to the extent of surface damage resulting from the localized plastic deformation in slip bands.

\section{Acknowledgments}

The authors are grateful to the French Ministry of Higher Education and Research, Region Picardie in France, Henan Provincial Research Bureau and NSF of China (No. $15 \mathrm{~A} 460030$ and 51650110502) for their financial support.

\section{REFERENCES}

1. Suresh, S. Fatigue of Materials, Second ed., Cambridge University Press, Cambridge, 1998. https://doi.org/10.1017/CBO9780511806575

2. Essmann, U., Gosele, U., Mughrabi, H. A Model of Extrusions and Intrusions in Fatigued Metals. 1: Point-Defect Production and the Growth of Extrusions Philosophical Magazine A 44 (2) 1981: pp. $405-426$.

https://doi.org/10.1080/01418618108239541

3. Basinski, Z.S., Pascual, R., Basinski, S.J. Low Amplitude Fatigue of Copper Single Crystals-1: The Role of the Surface in Fatigue Failure Acta Metallurgica 31 (4) 1983: pp. 591-602.

https://doi.org/10.1016/0001-6160(83)90049-4

4. Risbet, M., Feaugas, X. Some Comments about Fatigue Crack Initiation in Relation to Cyclic Slip Irreversibility Engineering Fracture Mechanics 75 (11) 2008: pp. 3511-3519.

https://doi.org/10.1016/j.engfracmech.2007.04.014

5. Villechaise, P., Sabatier, L., Girard, J.C. On Slip Band Features and Crack Initiation in Fatigued 316L Austenitic Stainless Steel: Part 1: Analysis by Electron Back-Scattered Diffraction and Atomic Force Microscopy Materials Science \& Engineering A 323 (1-2) 2002: pp. 377-385. https://doi.org/10.1016/S0921-5093(01)01381-8

6. Man, J., Petrenec, M., Obrtlík, K., Polak, J. AFM and TEM Study of Cyclic Slip Localization in Fatigued Ferritic X10CrA124 Stainless Steel Acta Materialia 52 (19) 2004: pp. $5551-5561$.

https://doi.org/10.1016/j.actamat.2004.08.014

7. Mughrabi, H. Cyclic Slip Irreversibilities and the Evolution of Fatigue Damage Metallurgical and Materials Transaction B 40 (6) 2009: pp. $431-453$. https://doi.org/10.1007/s11663-009-9240-4

8. Antolovich, S.D., Armstrong, R.W. Plastic Strain Localization in Metals: Origins and Consequences Progress in Materials Science 59 (1) 2014: pp. 1-160. https://doi.org/10.1016/j.pmatsci.2013.06.001

9. Feaugas, X., Risbet, M., Pilvin, P. Multiscale Effects in Fatigue of Metals, Ecole Polytechnique, in: Euromech 505, Palaiseau, 2010 .

10. Magnin, T., Driver, J.H., Lepinoux, J., Kubin, L.P. Aspects Microstructuraux De La Déformation Cyclique Dans Les Métaux Et Alliages C.C Et C.F.C. 1. - Consolidation Cyclique Revue de Physique Appliquée 19 (7) 1984: pp. $467-482$. https://doi.org/10.1051/rphysap:01984001907046700

11. Bayerlein, M., Mughrabi, H. The Formation of Wither Tongue - or Ribbon-Like Extrusions in Fatigue Copper Polycrystals Acta Metallurgical Et Materilia 39 (7) 1991: pp. 1645-1650. https://doi.org/10.1016/0956-7151(91)90252-V

12. Repetto, E.A., Ortiz, M. A Micromechanical Model of Cyclic Deformation and Fatigue-Crack Nucleation in F.C.C. Single Crystals Acta Materialia 45 (6) 1997: pp. $2577-2595$. https://doi.org/10.1016/S1359-6454(96)00368-0

13. Wang, Y., Meletis, E.I., Huang, H. Quantitative Study of Surface Roughness Evolution During Low-Cycle Fatigue of 316L Stainless Steel Using Scanning White Light Interferometric (Swli) Microscopy International Journal of Fatigue 48 (1) 2013: pp. $280-288$. https://doi.org/10.1016/j.ijfatigue.2012.11.009

14. Gadelmawla, E.S., $\quad$ Koura, M.M., $\quad$ Maksoud, T.M.A., Elewa, I.M., Soliman, H.H. Roughness Parameters Journal of Materials Processing Technology 123 (1) 2002: pp. $133-145$. https://doi.org/10.1016/S0924-0136(02)00060-2

15. ISO 25178-2. Geometrical Product Specifications (GPS)-Surface Texture: Areal-Part 2: Terms, Definitions And Surface Texture Parameters, 2012.

16. Keppel, G., Sauffley, W.H. Introduction to Design and Analysis, W.H. Freeman and Company, New York,1980.

17. Efron, B., Tibshirani, R. An Introduction to the Bootstrap, Chapman and Hill, New York,1993. https://doi.org/10.1007/978-1-4899-4541-9

18. Mughrabi, H. Introduction to the Viewpoint Set on: Surface Effects in Cyclic Deformation and Fatigue Scripta Metallurgica Et Materialia 26 (10) 1992: pp. 1499-1504. https://doi.org/10.1016/0956-716X(92)90246-B

19. Ohashi, T., Barabash, R.I., Pang, J.W.L., Ice, G.E., Barabash, O.M. X-ray Microdiffraction and Strain Gradient Crystal Plasticity Studies of Geometrically Necessary Dislocations Near a Ni Bicrystal Grain Boundary International Journal of Plasticity 25 (5) 2009: pp. $920-941$.

https://doi.org/10.1016/j.ijplas.2008.04.009

20. Sangid, M.D., Maier, H.J., Sehitoglu, H. The Role of Grain Boundaries on Fatigue Crack Initiation-An Energy Approach International Journal of Plasticity 27 (5) 2011: pp. $801-821$. https://doi.org/10.1016/j.ijplas.2010.09.009

21. Pineau, A., Antolovich, S.D. High Temperature Fatigue of Nickel-Base Superalloys - A Review with Special Emphasis on Deformation Modes and Oxidation Engineering Failure Analysis 16 (8) 2009: pp. 2668-2697.

https://doi.org/10.1016/j.engfailanal.2009.01.010

22. Chan, K.S. Roles of Microstructure in Fatigue Crack Initiation International Journal of Fatigue 32 (9) 2010: pp. $1428-1447$. https://doi.org/10.1016/j.ijfatigue.2009.10.005

23. Sriram, T.S., Fine, M.E., Chung, Y.W. STM and Surface Analytical Study of the Effect of Environment on Fatigue Crack Initiation in Silver Single Crystals 2: Effects of Oxygen Partial Pressure Scripta Metallurgica Et Materialia 24 (2) 1990: pp. $279-284$.

https://doi.org/10.1016/0956-716X(90)90256-G 